\title{
Isolated Cardiac Hydatidosis with Rare Involvement of Inter-Ventricular Septum
}

\author{
Kishor Taori, Ajinky Patil*, Lalit Garg, Mansi Jain, Jawhar Rathod, Priya Tembhare, \\ Amit Disawal, Ramesh Parate, Shyam Chhadi \\ Department of Radiodiagnosis, Government Medical College, Nagpur, India \\ Email: *ajinky_gmc@yahoo.co.in
}

Received 6 April 2014; revised 16 May 2014; accepted 6 July 2014

Copyright (C) 2014 by authors and OALib.

This work is licensed under the Creative Commons Attribution International License (CC BY). http://creativecommons.org/licenses/by/4.0/

(c) (i) Open Access

\begin{abstract}
Isolated Cardiac hydatidosis is a rare occurrence [1]. Involvement of left ventricle is more common followed by right ventricle, interventricular septum, left atrium, right atrium and interatrial septum. Here, we present a case report of 26-year-old male patient who was suspected to have left ventricle cystic lesion on 2D-Echocardiography which was confirmed to be Hydatid cyst situated in inter-ventricular septum on Magnetic resonance imaging which is itself a rare phenomenon.
\end{abstract}

\section{Keywords}

Hydatid, Interventricular Septum, Computed Tomography (CT), Magnetic Resonance Imaging (MRI)

\section{Subject Areas: Cardiology, Radiology \& Medical Imaging}

\section{Introduction}

Hydatid disease is a parasitic infection caused in humans by larval stage of Echinococcus granulosus complex, Echinococcus multilocularis or Echinococcus vogeli. Domestic dogs and cats are the primary host, while humans are intermediate host. Hydatidosis is more commonly noted involving liver (60\%) followed by lung (20\% - 30\%), however isolated Cardiac involvement is rare (0.5\% - 2\%) [2]. Involvement of left ventricle (60\%) is more common in cardiac hydatidosis followed by right ventricle (10\%), interventricular septum (4\%). Echocardiography, computed tomography and magnetic resonance imaging are boon to medical field for its diagnosis.

\section{Case Report}

A 26-year-old male patient presented to outpatient department with complaints of Dyspnoea, chest pain and

*Corresponding author.

How to cite this paper: Taori, K., Patil , A., Garg, L., Jain, M., Rathod, J., Tembhare, P., Disawal, A., Parate, R. and Chhadi, S. (2014) Isolated Cardiac Hydatidosis with Rare Involvement of Inter-Ventricular Septum. Open Access Library Journal, 1: e737. http://dx.doi.org/10.4236/oalib.1100737 
fever since 6 days. On clinical examination, respiratory system was clear, however on auscultation P2 was loud with parasternal heave present and central ventral pressure was raised. Chest radiograph revealed consolidatory patches in left mid \& lower zone (Figure 1(a)). Electrocardiography revealed features of right bundle branch block and right ventricular strain. Transthoracic echocardiography (Figure 1(b)) revealed multi-septated interventricular septal mass lesion compromising left and right ventricular cavity. Bronchogenic cyst was kept as differential diagnosis which was ruled out as it is congenital lesion noted in middle mediastinum extra cardiac location.

Cardiac Computed tomography and Magnetic resonance imaging was done to characterize the lesion. Cardiac computed tomography (Figure 1(c)) revealed a large, well-defined cystic lesion of approximate size of $8 \times 6.8 \times$ $7 \mathrm{cms}$ in transverse, antero-posterior and cranio-caudal axis respectively involving interventricular septum with peripheral wall calcifications and multiple peripherally arranged small cystic lesions within it. On Cardiac magnetic resonance imaging (Figure 1(d), Figure 1(e) \& Figure 1(f)), it revealed multiloculated cystic lesion in the interventricular septum with left ventricular compression and mild pericardial effusion. On T2 MRI, the cyst wall showed typical hypo intensity confirming the diagnosis of hydatid pericyst.

In view of above imaging features patient was diagnosed as having intra cardiac hydatid cyst involving interventricular septum.

However, on further evaluation with ultrasonography abdomen no other hydatid lesion was found.

On follow up, patient underwent cardio-pulmonary bypass surgery (Figure 1(g)) and many small cysts (Figure 1(h)) were retrieved and sent for histopathological analysis. Patient is recovering postoperatively with alleviation in chest pain, Dyspnea and fever.

\section{Discussion}

Hydatid disease is a parasitic infection caused in humans by larval stage of Echinococcus granulosus complex, Echinococcus multilocularis or Echinococcus vogeli. Domestic dogs and cats are the primary carriers. Humans are intermediary when they eat unwashed and inadequately cooked vegetables and swallow ova of the parasite. After digestion, embryo is released into gastrointestinal tract which gains entry into liver through portal circulation [3]. Parasite gives rise to cyst which consists of pericyst formed by host tissue encompassing the endocyst of larval origin. The cyst is covered by multipotential germinal layer inside the laminated layer or hyaline layer, which gives rise to production of brood capsules and protoscolices [4].

Isolated cardiac hydatid cyst is rare phenomenon [1] with involvement of inter-ventricular septum is even more rare occurrence. Larvae reach heart either via coronary circulation or through pulmonary veins [5]. After reaching heart, they slowly form mature cyst usually in sub-epicardial location. Rarely do they occur in subendocardial area with intracavitary expansion [5].

Clinical features are quite variable. Cysts have slow growth rate because of which patient is asymptomatic for long period of time. Symptoms when present depend upon the location of the cyst. Subepicardial cyst usually present with precordial pain due to compression of coronaries [6]. They may rupture into pericardial cavity causing pericarditis, tamponade, anaphylaxis and death [6] [7]. Even subendocardial cyst may present with chest pain and they may also rupture causing anaphylaxis reaction, death and pulmonary embolism [7]. Those with intracavitary extension may interfere with valvular function causing stenosis or incompetence [6], whereas rhythm disturbances are observed with interventricular septal cyst [6].

Amongst imaging modalities, echocardiography, computed tomography and magnetic resonance imaging play a very important role. All of them will provide you with information regarding cystic nature of the lesion and its relation with the cardiac chambers. But amongst this three modalities also, each one has their own advantage. Computed tomography will inform you about the calcifications while magnetic resonance imaging will tell you about the anatomic location, nature of the internal and external structures and it is also the technique for post treatment follow up [8]. On MRI, T1W hypo intense and T2W hyper intense oval lesion with a peripheral hypo intense ring on T2W sequence (pericyst) [9] [10]. Most specific signs for the diagnosis of hydatid cyst include wall calcifications, presence of daughter cysts and internal membranous structures.

Management consists of both medical and surgical. However, surgical extirpation of lesion under cardiopulmonary bypass is recommended [3] [4]. Medical management consist of providing with anti-parasitic agent (Albendazole) especially in asymptomatic elderly patients [11], pre and post operated patients to avoid surgical dissemination and recurrence. 


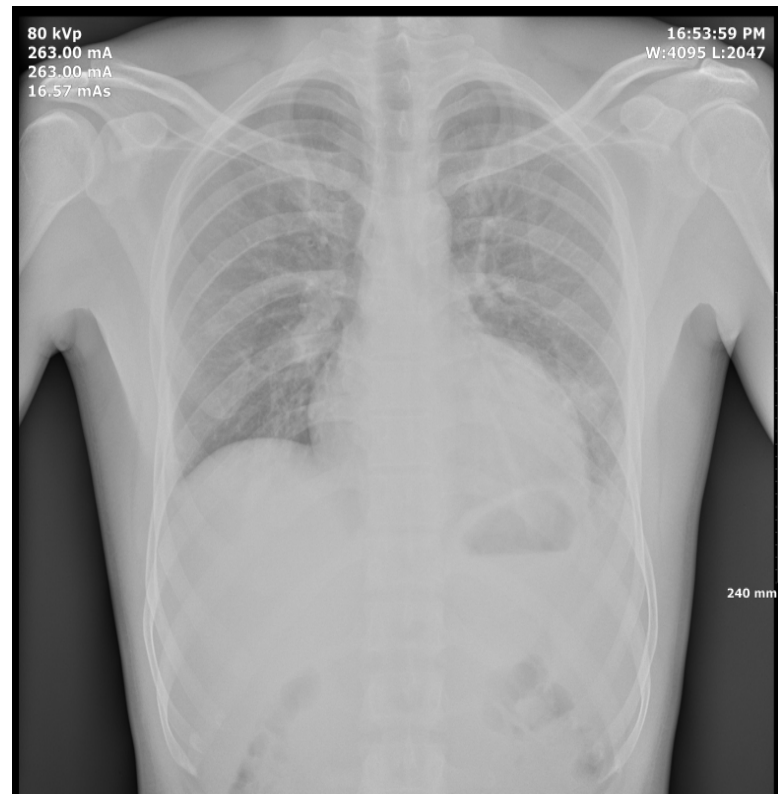

(a)

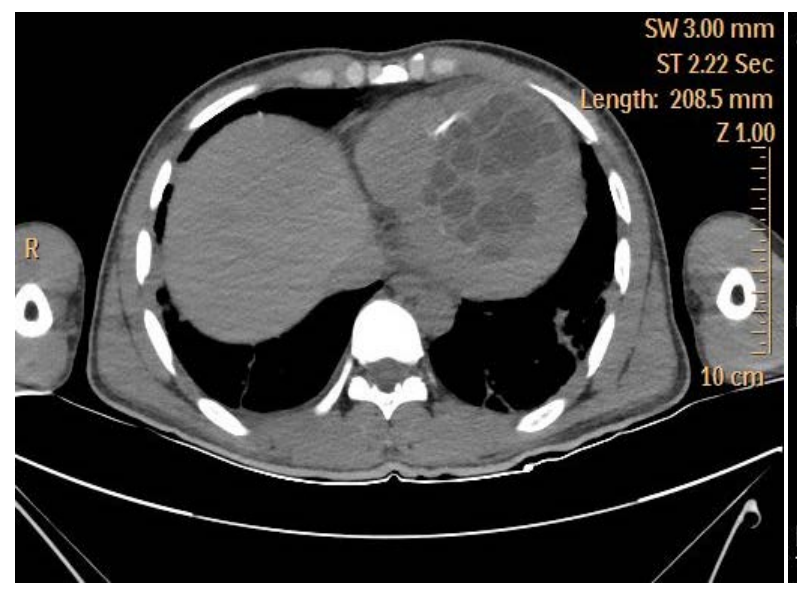

(c)

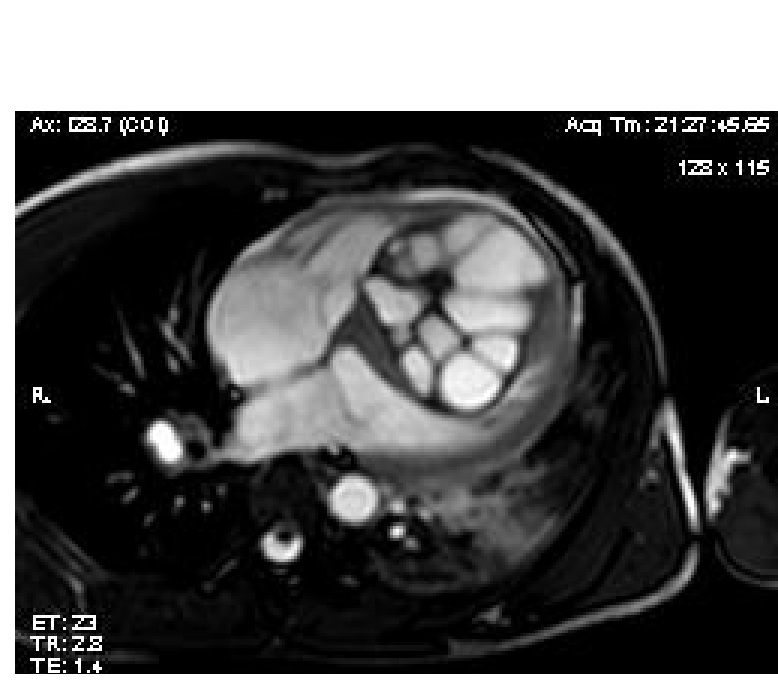

(e)

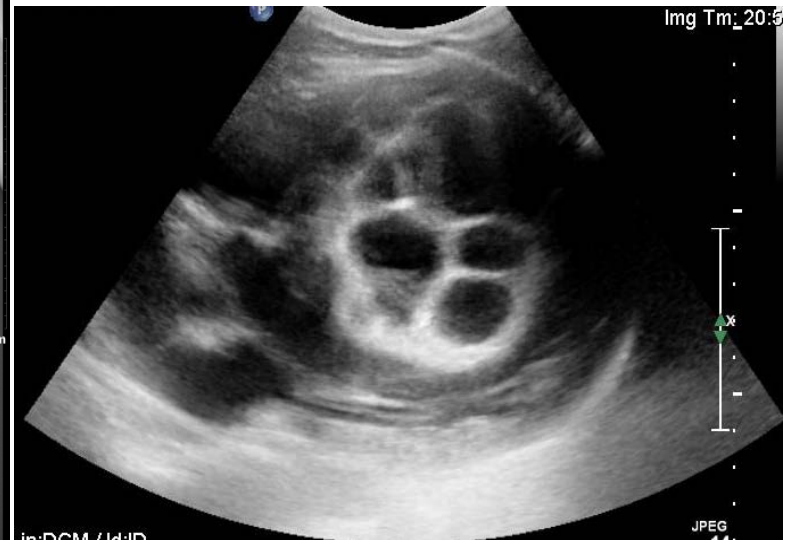

Img Tm:20:

(b)

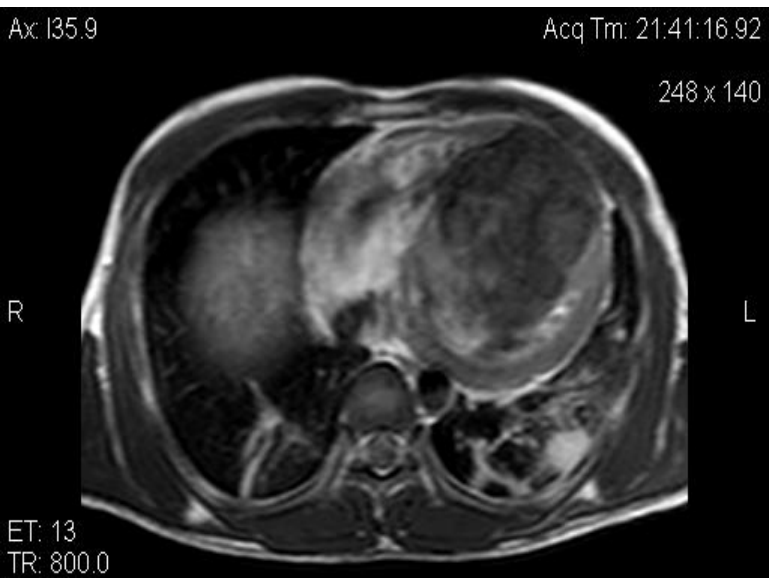

(d)

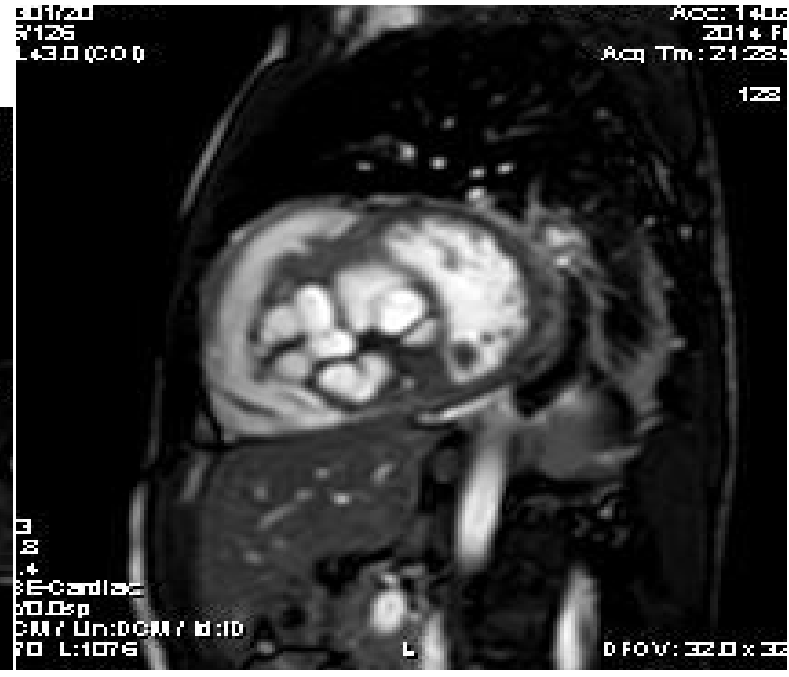

(f) 


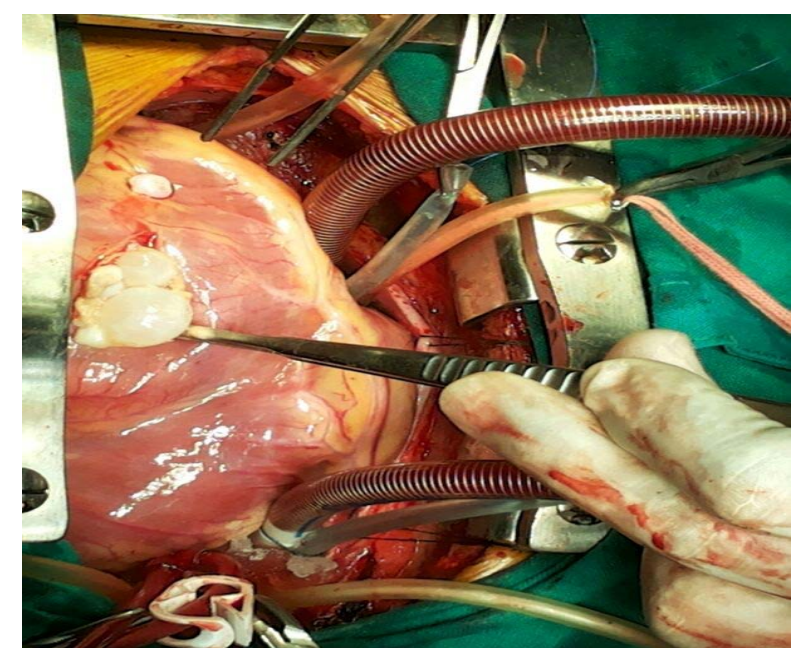

(g)

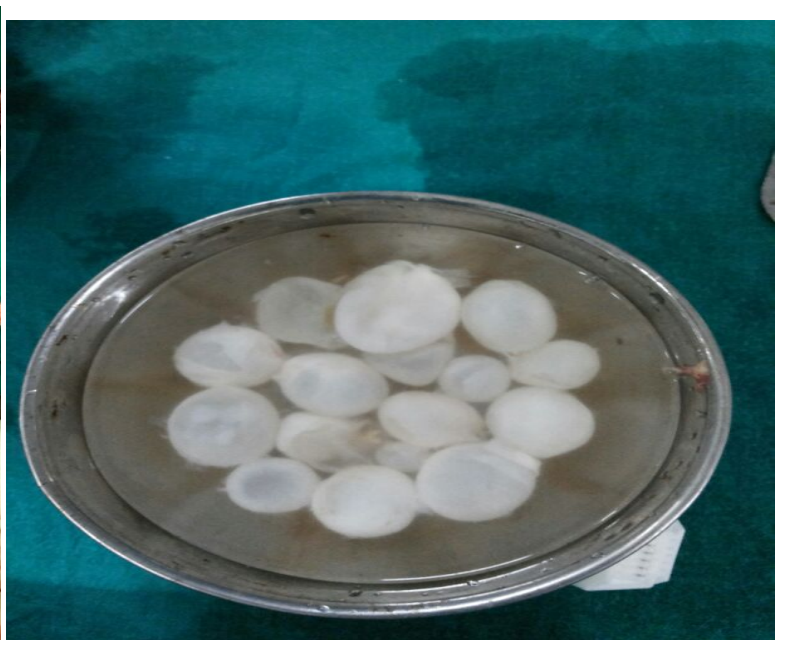

(h)

Figure 1. (a) Chest radiography showing consolidatory patches in left lower zone; (b) showing multi-loculated cystic lesion in interventricular septum; (c) Axial image of CT Thorax plain revealing large intracardiac cyst with peripheral wall calcifications and multiple daughter cysts within; (d) Axial T1W C++ sequence showing non-enhancing cyst in interventricular septum with daughter cysts; (e) BTFE sequence confirming the finding in axial view; (f) BTFE sequence confirming the finding in sagittal view; (g) cardio-pulmonary bypass surgery; (h) retrieved multiple small hydatid cysts.

In summary, we present a rare case of isolated cardiac hydatidosis with involvement of interventricular septum that was asymptomatic till the cyst has grown till such a large size with imaging modalities playing a vital role in its diagnosis.

\section{Acknowledgements}

Suresh Dhakate, MD, Anand Hatgaonkar, MD.

\section{Conflicts of Interest Statement}

There is no conflict in author or acknowledged persons.

\section{References}

[1] Yalliniz, H., Tokcan, A., Salih, O.K. and Ulus, T. (2006) Surgical Treatment of Cardiac Hydatid Disease: A Report of 7 Cases. Texas Heart Institute Journal, 33, 333-339.

[2] Perez-Gomez, F., Duran, H., Tamamer, S., Perrote, J.L. and Blanes, A. (1973) Cardiac Echinococcosis: Clinical Pictures and Complications. Heart, 35, 1326-1331. http://dx.doi.org/10.1136/hrt.35.12.1326

[3] Onursal, E., Elmaci, T.T., Tireli, E., Dindar, A., Atilgan, D. and Ozcan, M. (2001) Surgical Treatment of Cardiac Echinococcosis: Report of Eight Cases. Surgery Today, 31, 325-330. http://dx.doi.org/10.1007/s005950170153

[4] Gormus, N., Yeniterzi, M., Telli, H.H. and Solak, H. (2004) The Clinical and Surgical Features of Right-Sided Intracardiac Masses Due to Echinococcosis. Heart Vessels, 19, 121-124. http://dx.doi.org/10.1007/s00380-003-0732-x

[5] Kaplan, M., Demirtas, M., Cimen, S. and Ozler, A. (2001) Cardiac Hydatid Cysts with Intracavitary Expansion. The Annals of Thoracic Surgery, 71, 1587-90. http://dx.doi.org/10.1016/S0003-4975(01)02443-2

[6] Kardaras, F., Kardara, D., Tselikos, D., Tsoukas, A., Exadactylos, N., Anagnostopoulou, M., Lolas, C. and Anthopoulos, L. (1996) Fifteen Year Surveillance of Ecchinococcal Heart Disease from a Referral Hospital in Greece. European Heart Journal, 17, 1265-1270. http://dx.doi.org/10.1093/oxfordjournals.eurheartj.a015045

[7] Tuncer, E., Tas, S.G., Mataraci, I., Tuncer, A., Donmez, A.A., Aksut, M. and Yakut, C. (2010) Surgical Treatment of Cardiac Hydatid Disease in 13 Patients. Texas Heart Institute Journal, 37, 189-193.

[8] Oueslati, S., Said, W., Saaidi, I., et al. (2006) Imaging Cardiac Hydatid Cysts: 8 Cases. La Presse Médicale, 35, 11621166. http://dx.doi.org/10.1016/S0755-4982(06)74773-X

[9] Kotoulas, G.K., Magoufis, G.L., Gouliamos, A.D., et al. (1996) Evaluation of Hydatid Disease of the Heart with Mag- 
netic Resonance Imaging. Cardiovascular and Interventional Radiology, 19, 187-189. http://dx.doi.org/10.1007/BF02577618

[10] Yague, D., Lozano, M.P., Lample, C., Nunez, M.E. and Sanchez, F. (1998) Bilateral Hydatid Cyst of Pulmonary Arteries: MR and CT Findings. European Radiology, 8, 1170-1172. http://dx.doi.org/10.1007/s003300050528

[11] Losanoff, J.E., Richman, B.W. and Jones, J.W. (2002) Cardiac Hydatid Cysts. The Annals of Thoracic Surgery, 73, 699-700. http://dx.doi.org/10.1016/S0003-4975(01)03352-5 